\title{
Special Nuclear Material Identification Through One-Minute Measurement with a New Backpack Radiation Device in Real Scenario Conditions
}

\author{
Giacomo Mangiagalli $^{1 *}$, Massimo Morichi ${ }^{1}$, Andrea Pepperosa $^{1}$, Luca Stevanato $^{2}$, Isacco Bonesso $^{2}$ \\ ${ }^{1}$ CAEN SpA, Via Vetraia 11, Viareggio (LU) 55049, Italy \\ ${ }^{2}$ Padova University, Via Marzolo 8, Padova (PD) 35121, Italy
}

Corresponding Author Email: g.mangiagalli@caen.it

https://doi.org/10.18280/ijsse.110416

Received: 8 February 2021

Accepted: 17 July 2021

\section{Keywords:}

backpack radiation device (BRD), homeland security, material out of regulatory control (MORC) neutron source identification, plutonium, special nuclear material (SNM), uranium

\begin{abstract}
The constant concerns in global nuclear safety, aimed at deterring and combating the illicit trafficking of Material Out of Regulatory Control (MORC) and its possible use in criminal acts has raised the necessity of new detection solutions with higher efficiency and resolution to provide a high level of accuracy in the report to the authorities. Today's radioactive isotope identifiers perform gamma spectroscopy identification and, sometimes, neutron counting. This paper presents the results of measurements performed in real-scenario conditions with a new type of portable radioactive isotope identifier for the detection and identification of both gamma and neutron sources. Its singular features are: 1) the capability to identify sources through the detection of neutrons, discriminating spontaneous fission sources (Cf-252), $\alpha-n$ sources (Am/Be, Am/Li) and nuclear material containing mix of isotopes of plutonium or uranium 2) the capability to make cross correlation between gamma and neutron measurements to achieve a higher level of accuracy in the identification of SNM that emits both neutrons and characteristics gammas. The test results are compared with international standards. The device exceeds the standard performance by triggering a neutron alarm for a $20.000 \mathrm{n} / \mathrm{s} \mathrm{Cf}-252$ source at a five times greater distance than the ANSI N42.34 one.
\end{abstract}

\section{INTRODUCTION}

This paper presents the new features of a portable radioactive isotope identifier for the detection and identification of both gamma and neutron emitting radionuclides, even multiple ones. This new technology was already introduced the first time in paper [1]. The new features introduced can be resumed in:

- the capability to identify sources through the detection of neutrons, discriminating spontaneous fission sources (Cf252), $\alpha-n$ sources $(\mathrm{Am} / \mathrm{Be}, \mathrm{Am} / \mathrm{Li})$ and nuclear material containing mix of isotopes of plutonium or uranium (extensive tests results)

- the capability to make cross correlation between gamma and neutron measurements to achieve a higher level of accuracy in the identification of SNM that emits both neutron and characteristic gamma lines

Many measurements have been performed in several accredited laboratories with different mix of SNM sources.

Different measurement conditions were tested at gradually increasing levels of difficulty, adding, for example: shields, moderators, masking gamma sources and a mix of the above mentioned. Before reporting the tests setup with their results there is an introduction on the instrument technology and the implemented algorithm.

\section{DEFINITION OF THE PROBLEM}

Nowadays nuclear threats are still an actual problem, as evidenced by several organization such as the International Atomic Energy Agency (IAEA), INTERPOL and the World Customs Organization [2-5]. The risk that nuclear or radioactive materials could be used in a criminal act remains high and is regarded as a serious threat to international stability and security [6]. For this reason, international organizations such as the IAEA are pursuing the objective of combating illicit nuclear trafficking and strengthen nuclear security as reported in its security plan [7]. From 1993 to the 31 December 2018, according to the IAEA Incident and Illicit Trafficking Database (ITDB) 3497 incidents were reported by its participating States. All these incidents were divided into the following 3 groups:

- 285 incidents that are confirmed, or likely to be connected with trafficking or malicious use of nuclear and other radioactive material;

- 965 incidents for which there is insufficient information to determine a relation with trafficking or malicious use;

- 2247 incidents that are not related to trafficking or malicious use.

Since the knowledge to create a nuclear device (whether it is an explosive or a radioactive material dispersal or radiationemitting one) is nowadays into public domain, preventing terrorist groups from accessing sufficient amount of nuclear or radioactive material it is essential to prevent possible nuclear threats [8-12]. For this reason, in recent years extensive investment has been earmarked for the purchase of detection systems aimed to detect and interdict the material out of regulatory control. 


\section{STATE OF THE ART}

Given the importance of nuclear and radiological security issues, the market currently offers different kind of instruments designed to monitor, detect and identify nuclear and radioactive materials. Among these devices, mobile detection systems (e.g. hand-held or backpack based instruments) are interesting for their portability and ease of use. Nowadays, standard mobile detection systems rely on high purity germanium (HPGe) or inorganic crystal scintillators (e.g. $\mathrm{NaI}(\mathrm{Tl}), \mathrm{CsI}(\mathrm{Tl})$ and $\mathrm{LaBr} 3(\mathrm{Ce})$ ) for gamma ray detection and on $3 \mathrm{He}$ tubes or inorganic scintillators doped with $6 \mathrm{Li}$ or $10 \mathrm{~B}$ for neutron counting

\section{PSD ALGORITHM FOR SNM IDENTIFICATION}

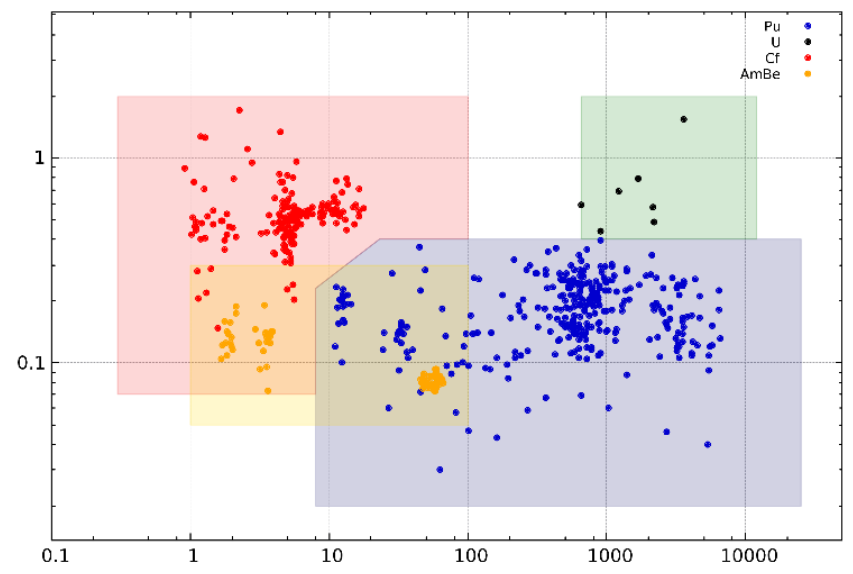

Figure 1. Neutron source identification algorithm results

The device used for the tests presented in this paper is equipped with an organic liquid scintillator with excellent Pulse Shape Discrimination (PSD) proprieties for the simultaneous detection of gamma rays and neutrons and a midhigh resolution inorganic crystal for gamma spectroscopy identification. The liquid scintillator detector can discriminate gammas from neutrons through a PSD technique. The PSD signal processing is currently performed by using complex and expensive read-out systems. The system here presented makes use of a CAEN DT5790 (Figure 2), an advanced digital Multi Channel Analyzer (MCA) running a Digital Pulse Processing (DPP) firmware in the FPGA. The PSD firmware performs online fast discrimination of neutrons from gammas, enabling individual alarms for each kind of particle. The PSD algorithmis based on an digital dual gate charge integration technique able to sustain high counting rates. It performs double integration of both prompt and total charge, selftriggering, input signal baseline calculation and pedestal subtraction for energy calculation and pile-up rejection. The anode signals of both detectors are fed directly into the CAEN DT5790 digitizer ( $2 \times 250 \mathrm{MS} / \mathrm{s}$ 12-bit). The DPP-PSD algorithm provides on-line data for each event like: (a) the time stamp, (b) the total charge integration of the signal, (c) the partial charge integration of the signal used for PSD and (d) the possibility of storing a selected part of the digitized signal. The PSD capabilities of the detector are so exploited in real-time to discriminate gamma from neutrons. The same algorithm has been designed and implemented by CAEN and is today in use at IAEA safeguard department in the Fast Neutron Collar Monitor for fresh fuel verification (as described in Ref. [13]). This device can detect radioactive source as Special Nuclear Material (SNM), medical, industrial and Naturally Occurring Radioactive Material (NORM). The main ability of this instrument is not limited to counting neutrons surrounding the device but it can also identify the neutron sources. In addition, it can discriminate between different fission sources (Cf-252) $\alpha$-n sources ( $\mathrm{Am} / \mathrm{Be}, \mathrm{Am} / \mathrm{Li})$ and nuclear material containing mix of isotopes of plutonium or uranium. The identification algorithm performs a subtraction of environmental background spectrum from the one-minute spectrum accumulated during the identification measurement. Then, multiplicity rate counting and analysis of energy spectrum of neutrons are performed on the obtained spectrum. Details on the procedures used by the algorithm can't be revealed because they are object of a patent and are intellectual property of CAEN SpA.

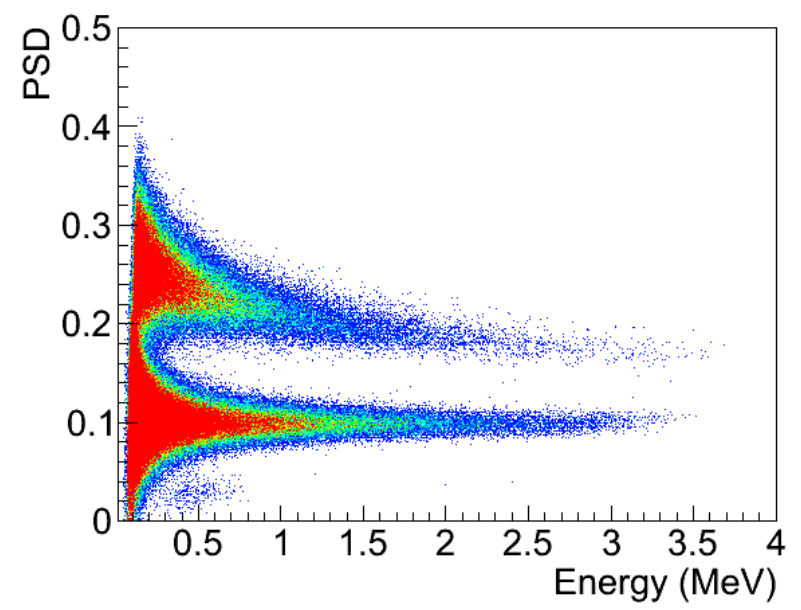

Figure 2. CAEN DT5790 PSD Plot obtained with a EJ309 liquid scintillator detector coupled to a Hamamatsu flat panel

The measurements characteristics were already introduced in the [1] and they are listed here for convenience:

- A moving average is used to integrate the last three minutes of natural background in order to set individual thresholds for neutron and gamma counts;

- Alarms are triggered separately when the respective rate exceed the alarm thresholds. These thresholds are calculated to allow detection with 95\% detection probability at $95 \%$ confidence level for a dose rate on the front face of the scintillator of at least $50 \mathrm{nSv} / \mathrm{h}$;

- The neutron source detection has been tested also in high gamma ray fields up to $0.1 \mathrm{mSv} / \mathrm{h}$.

- The novel discrimination algorithm allows also a neutron source classification

- The measured FoM (see caption of Figure 3) with an energy window of $480 \pm 75 \mathrm{keV}$ is 1.73 . the FoM "Figure of Merit" indicates the performance of the Pulse Shape Discrimination. The graph of the FoM is a projection of the $y$ axis of the PSD plot on the $\mathrm{x}$ axis thus obtaining a PSD vs count plot with two Gaussian distribution, one for the gamma and one for the neutron (see Figure 4).

The FoM is defined as:

$$
F O M=S /(\Gamma n+\Gamma g)
$$

where, $\mathrm{S}$ is the distance between the two centroids of neutron and gamma gaussian distribution and $(\Gamma \mathrm{n}+\Gamma \mathrm{g})$ is the sum of gamma and neutron FWHMs. 


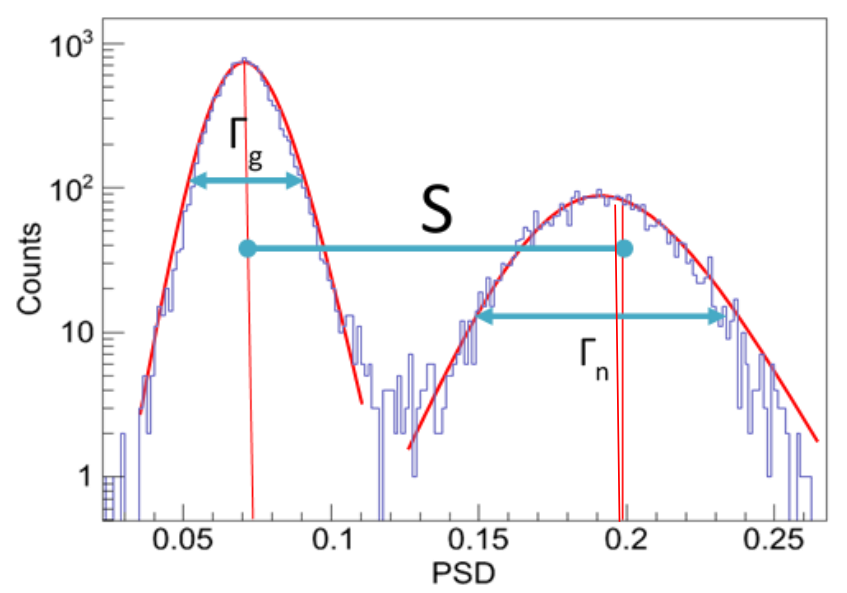

Figure 3. The FoM plot obtained by projecting the PSD plot on the $\mathrm{x}$ axis. FWHMs and separation between centroids are shown in the plot

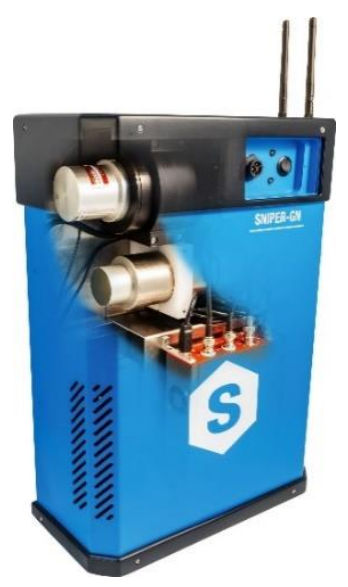

Figure 4. New compact set-up containing the DT5790, two detectors, the LiFePO4 Battery and the Single Board Computer (SBC). Data are transmitted through Wi-Fi

\section{NEUTRON SOURCE IDENTIFICATION ALGORITHM}

As introduced in [1] the first tests were performed in a laboratory configuration, with the MCA and the detectors arranged on a desk and with the power supply provided by the domestic plug. The algorithm was run on a desktop pc with a powerful CPU and dedicated Control Software. The second step was made to target the engineered final product stronger constraints. the electronics and the detectors were mounted inside an aluminum box and the apparatus was powered with a $\mathrm{LiFePO}_{4}$ battery (25 Ah@12 V). The computer was replaced with a Single Core Board with ARM processor which run a revision of the software optimized for lower resource consumption. In this configuration the system became portable. For the new measurement campaign, object of this paper, more prototypes with the same arrangement were produced, to test also the reproducibility of the results. Homeland security ANSI and IEC standards were taken in consideration to understand where this kind of product can be included. The most suitable ones are:

- IEC 62327 Hand Held instruments for the detection and identification of radionuclides;

- IEC 62438, Radiation protection instrumentation - Mobile instrumentation for the measurement of photon and neutron radiation in the environment;

- ANSI 42.34 Hand Held instruments for the detection and identification of radionuclides;

- $\quad$ ANSI N42.43, American National Standard Performance Criteria For Mobile And Transportable Radiation Monitors Used For Homeland Security;

- $\quad$ ANSI N42.53, American National Standard Performance Criteria for Backpack-Based Radiation-Detection Systems Used for Homeland Security.

In addition, other technical guides are edited by the IAEA:

- $\quad$ IAEA NNS 1: Technical and Functional Specifications for Border Monitoring Equipment;

- IAEA TECDOC 1363: Guidelines for radioelement mapping using gamma ray spectrometry data.

Considering the European standard, the requirements for gamma and neutron alarm and identification are:

- Gamma alarm triggered in 1 second for a source moving at a speed of $0.5 \mathrm{~m} / \mathrm{s}$ producing a radiation field of 500 $\mathrm{nSv} / \mathrm{h}$ above the background at the reference point (distance between reference point and source cannot be less than $1 \mathrm{~m}$ );

- Neutron alarm triggered in 2 seconds for a 20.000 neutrons/s Cf-252 source surrounded by $4 \mathrm{~cm}$ of Highdensity polyethylene at $25 \mathrm{~cm}$ of distance from the reference point;

- 1 minute or less for source identification.

\section{MEASUREMENT CAMPAIGNS}

Many different tests were performed with the device in the new compact configuration. Most of the measurements were focused on the neutron source identification (see Figure 1). The identification measurement was performed using a oneminute acquisition. This is the maximum time allowed by the standard.

\section{Test Session 1}

Two different sources were available at the laboratory and were used in this session. Each source was composed by a mixture of Plutonium isotopes (such as $\mathrm{Pu}-242, \mathrm{Pu}-241, \mathrm{Pu}-$ 240, Pu-239, Pu-238) and their decay products. The two sources differed in their enrichment level in Pu-239. These sources were incapsulated in a cylindrical shell of $0.6 \mathrm{~cm}$ stainless steel (see Table 1). For security purposes CAEN SpA is not allowed to share more information on the source composition and amounts. The neutron yields at the measurement date were:

Table 1. Neutron emission rate at session 1

\begin{tabular}{cc}
\hline Source name & Neutrons/s emission at the test date \\
\hline Source-1 & 4,169 \\
Source-2 & 3,065 \\
\hline
\end{tabular}

Concerning the neutron alarm there are not any specification on the neutron emission for the $\mathrm{Pu}$ in the standard. For this reason the same parameters used for the Cf- 252 were kept.

Moreover, There are not specifications or limitation on the parameters for the identification performed through neutron detection because there is not any instrument that can perform this type of measurement yet. For the neutron static measurement the standard reference of a $\mathrm{Cf}-252$ source 
emitting $20.000 \mathrm{n} / \mathrm{s}$ placed at $25 \mathrm{~cm}$ has been used. The standard distance $(25 \mathrm{~cm})$ has been rescaled proportionally to the neutron emission rate of the Plutonium source. Considering a neutron emission that cover the full available solid angle $(4 \pi)$ the proportion used is:

$$
\frac{20.000\left[\frac{n}{s}\right]}{4 \pi *(25[\mathrm{~cm}])^{2}}=\frac{n \text { emission source } i\left[\frac{n}{s}\right]}{4 \pi *\left(\text { distance }_{i}^{\text {rif }}[\mathrm{cm}]\right)^{2}}
$$

where the $n$ emission source $e_{i}$ are the emission rates listed in the previous table and the distance ${ }_{i}^{\text {rif }}$ are the new reference distances scaled on the used sources. The experimental apparatus has been placed in the different laboratories following the indications listed below:

- The device and source were placed on a support at least $50 \mathrm{~cm}$ above the ground to reduce the environmental radioactivity contribution to the background and avoid soil reflections of neutrons.

- The space between sources and device was empty to reduce the reflection of neutrons

- $\quad$ The space around the measurement region was empty, to reduce the reflection of neutrons

- The device/source distance for the first measurement was the one calculated with formula (1). If the identification result was correct the following steps were followed:

○ Increase the device/source distance by keeping the same shielding

- Increase the shielding between the source and the device by keeping the same source distance

- Increase both

In the following tables the results of the identification through neutron detection are reported. There is not a standard or any requirement on the identification of source through the neutron detection because there is not any instrument that can perform this kind of measurements. The gamma spectrum identification result is not reported to not confuse the reader. It is worth noting that gamma measurement performance has been tested in another measurement session and the device exceeds the standard performance. The results of gamma identification in this case would have only double confirmed the results of the neutron identification measurement. In some of the reported measurements the neutron identification algorithm was forced to start manually because the source/detector distance was too high to trigger the neutron alarm (statistic too low). This fact shows that the neutron identification algorithm is so performant that it can identify the neutron source also when the source/detector distance is so big that the counting statistic is not enough to trigger the alarm.

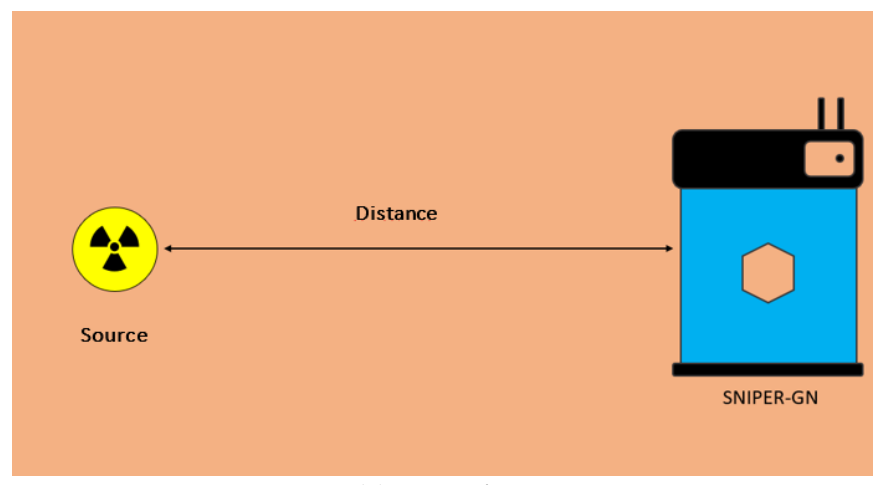

(a) Top view

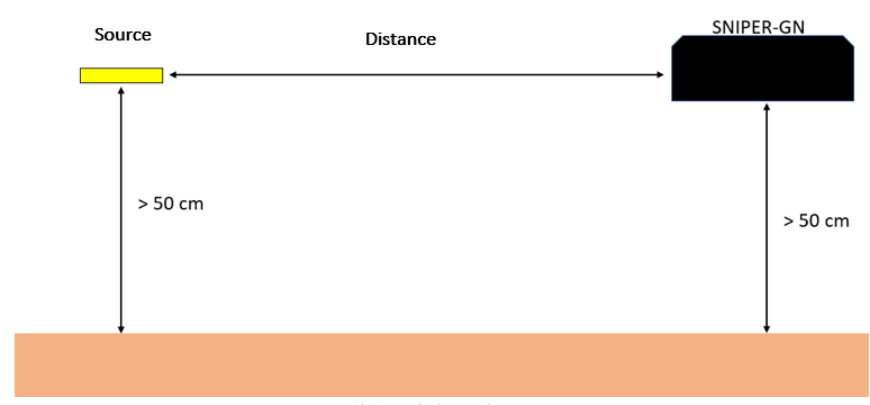

(b) Side view

Figure 5. Experimental setup

Source 1

For source 1 the distance ${ }_{i}^{\text {rif }}$ was $10 \mathrm{~cm}$. Results are listed in Table 2.

Table 2. Test results for the source 1 in different measurement conditions

\begin{tabular}{lcc}
\hline distance $(\mathrm{cm})$ & Shielding & Identification/trials \\
\hline 15 x standard & - & $150 / 150$ \\
15 x standard & Poly $5 \mathrm{~cm}$ & $14 / 15$ \\
15 x standard & Pb $5 \mathrm{~cm}$ & $14 / 15$ \\
25 x standard & - & $30 / 30$ \\
\hline
\end{tabular}

The maximum distance reached was $250 \mathrm{~cm}$. It was 25 times greater than the standard distance.

Source 2

For source 2 the distance ${ }_{i}^{\text {rif }}$ was $10 \mathrm{~cm}$.

Results are listed in Table 3.

Table 3. Test results for the source 2 in different measurement conditions

\begin{tabular}{lcc}
\hline distance $(\mathrm{cm})$ & Shielding & Identification/trials \\
\hline $\mathbf{1 5} \times$ standard & - & $9 / 9$ \\
$\mathbf{1 5} \times$ standard & Poly $5 \mathrm{~cm}$ & $8 / 8$ \\
$\mathbf{1 5}$ x standard & $\mathrm{Pb} 5 \mathrm{~cm}$ & $6 / 8$ \\
$\mathbf{2 0} \times$ standard & - & $8 / 8$ \\
$\mathbf{2 5} \times$ standard & - & $12 / 15$ \\
\hline
\end{tabular}

The maximum distance reached was $250 \mathrm{~cm}$ with a success rate of $80 \%$ due to the lower neutron flux respect to source 1 . It was 25 times greater than the standard distance.

\section{Test Session 2}

The source available at the lab were a Cf-252 source and a $\mathrm{Am} / \mathrm{Be}$ source. The neutron yields at the measurement date are listed in Table 4.

Table 4. Neutron emission rate at session 2

\begin{tabular}{cc}
\hline Source name & Neutron/s emission at the test date \\
\hline $\mathbf{C f - 2 5 2}$ & 65,69 \\
$\mathbf{A m B e}$ & 198,75 \\
\hline
\end{tabular}

The same considerations of the session 1 were applied here. In the following tables (see Table 5 for $\mathrm{Cf}-252$ source, see Table 6 for $\mathrm{Am} / \mathrm{Be}$ source) the results of the identification through neutron detection are reported.

\section{$\underline{\mathrm{Cf}-252}$}

For the Cf-252 the distance ${ }_{i}^{\text {rif }}$ was $45.5 \mathrm{~cm}$. 
Table 5. Test results for the Cf- 252 source in different measurement conditions

\begin{tabular}{ccc}
\hline distance (cm) & Shielding & Success/trials \\
\hline standard & Pb $5 \mathrm{~cm}+$ Poly $6 \mathrm{~cm}$ & $10 / 10$ \\
2 x standard & Poly $10 \mathrm{~cm}$ & $10 / 10$ \\
$\mathbf{4 . 5}$ x standard & - & $15 / 15$ \\
\hline
\end{tabular}

The maximum distance reached was $200 \mathrm{~cm}$. It was 4.5 times greater than the standard distance.

$\underline{\mathrm{Am} / \mathrm{Be}}$

For the $\mathrm{Am} / \mathrm{Be}$ the distance ${ }_{i}^{\text {rif }}$ was $80 \mathrm{~cm}$.

Table 6. Test results for the Am/Be source in different measurement conditions

\begin{tabular}{ccc}
\hline distance $(\mathbf{c m})$ & Shielding & Success/trials \\
\hline standard & - & $10 / 10$ \\
standard & $\mathrm{Pb} 5 \mathrm{~cm}+$ Poly $6 \mathrm{~cm}$ & $15 / 15$ \\
2 x standard & - & $15 / 15$ \\
\hline
\end{tabular}

The maximum distance reached was $160 \mathrm{~cm}$. It was 2 times greater than the standard distance.

Test Session 3

In this measurement session the same sources of the session 1 were used. In addition, for some measurements, a Cs-137 source with an activity of $4.5 \times 10^{5} \mathrm{~Bq}$ was added for masking purposes. The goals of this new session of measurements were:

- increase the difficulty of the measurement respect to session 1 by adding masking source or masking source plus shielding

- Test the first version of the cross-correlation algorithm that allows to double check the presence of SNM through both the neutron and the gamma measurements.

In the tables below the results of the identification measurement are reported. In the report column the nuclides coming from the neutron identification algorithm are reported with $a^{*}$, the nuclides coming from the gamma peak search algorithm performed on the mid-high resolution scintillator spectra are reported normally (without the *).
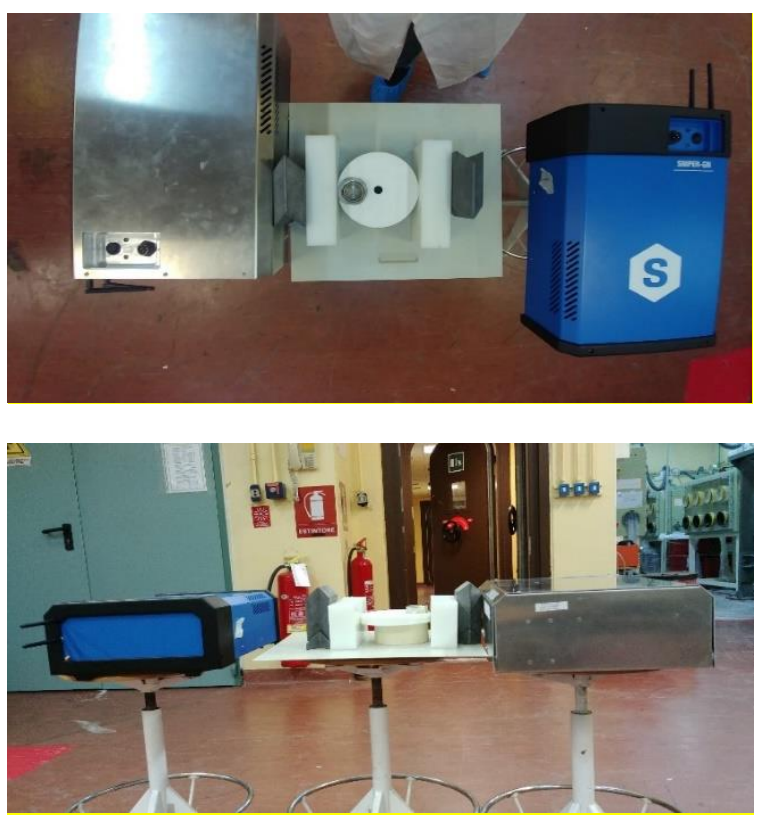

Figure 6. Experimental setup picture

\section{Source 1}

For source 1 the distance ${ }_{i}^{\text {rif }}$ was $10 \mathrm{~cm}$. Results are listed in Table 7.

Table 7. Test results for the source 1 in different measurement conditions

\begin{tabular}{|c|c|c|c|c|}
\hline $\begin{array}{l}\mathrm{N} \text { of } \\
\text { trials }\end{array}$ & $\begin{array}{c}\text { distance } \\
{[\mathrm{cm}]}\end{array}$ & $\begin{array}{c}\text { Shielding } \\
{[\mathrm{cm}]}\end{array}$ & Report & $\begin{array}{c}\text { Triggered } \\
\text { alarm }\end{array}$ \\
\hline 10 & 10 & $x^{3}=2$ & $\begin{array}{c}\mathrm{Pu} * \mathrm{Pu} \\
100 \% \mathrm{CL}\end{array}$ & $\mathrm{n}$ and $\gamma$ \\
\hline 15 & 10 & 5 Lead & $\begin{array}{c}\mathrm{Pu}^{*} \mathrm{Pu} \\
100 \% \mathrm{CL}\end{array}$ & $\mathrm{n}$ and $\gamma$ \\
\hline 17 & 10 & $\begin{array}{c}5 \text { Lead }+5 \\
\text { Poly }\end{array}$ & $\begin{array}{c}\mathrm{Pu} * \mathrm{Pu} \\
90 \% \mathrm{CL}\end{array}$ & $\mathrm{n}$ and $\gamma$ \\
\hline 10 & 40 & - & $\begin{array}{c}\mathrm{Pu} * \mathrm{Pu} \\
100 \% \mathrm{CL}\end{array}$ & $\mathrm{n}$ and $\gamma$ \\
\hline 10 & 40 & 5 Lead & $\begin{array}{c}\mathrm{Pu} * \mathrm{Pu} \\
80 \% \mathrm{CL}\end{array}$ & $\mathrm{n}$ and $\gamma$ \\
\hline 10 & 40 & $\begin{array}{c}5 \text { Lead }+5 \\
\text { Poly }\end{array}$ & $\begin{array}{c}\mathrm{Pu} * \mathrm{Pu} \\
80 \% \mathrm{CL}\end{array}$ & $\mathrm{n}$ and $\gamma$ \\
\hline
\end{tabular}

Source 2

For source 2 the distance ${ }_{i}^{\text {rif }}$ was $10 \mathrm{~cm}$.

Results are listed in Table 8.

Table 8. Test results for the source 2 in different measurement conditions

\begin{tabular}{|c|c|c|c|c|}
\hline $\begin{array}{l}\mathrm{N} \text { of } \\
\text { trials }\end{array}$ & $\begin{array}{l}\text { distance } \\
\text { (cm) }\end{array}$ & $\begin{array}{c}\text { Shielding } \\
\text { [cm] } \\
\text { /Exposure } \\
\text { from Cs- } \\
137[\mathrm{nSv} / \mathrm{h}]\end{array}$ & Report & $\begin{array}{c}\text { Triggered } \\
\text { alarm }\end{array}$ \\
\hline 11 & 50 & -0 & $\begin{array}{c}\mathrm{Pu} * \mathrm{Pu} 100 \% \\
\mathrm{CL} \\
\mathrm{Pu} * \mathrm{Pu} 90 \%\end{array}$ & $\mathrm{n}$ and $\gamma$ \\
\hline 5 & 25 & -452 & $\begin{array}{l}\text { CL Cs-137 } \\
100 \% \text { CL }\end{array}$ & $\mathrm{n}$ and $\gamma$ \\
\hline 5 & 25 & 5 Lead- & $\begin{array}{c}\mathrm{Pu}^{*} \\
\mathrm{Pu}{ }^{*} \mathrm{Cs}-137\end{array}$ & $\mathrm{n}$ \\
\hline 5 & 25 & 5 Poly 473 & $\begin{array}{c}100 \% \text { CL Pu } \\
90 \% \text { CL }\end{array}$ & $\mathrm{n}$ and $\gamma$ \\
\hline 5 & 10 & 5 Poly- & $\mathrm{Pu}^{*}$ & $\mathrm{n}$ \\
\hline 5 & 10 & $\begin{array}{l}5 \text { Lead }+5 \\
\text { Poly- }\end{array}$ & $\mathrm{Pu}^{*}$ & $\mathrm{n}$ \\
\hline 5 & 10 & 5 Lead 2963 & $\begin{array}{c}\mathrm{Pu} * \mathrm{Cs}-137 \\
100 \% \mathrm{CL} \mathrm{Pu} \\
100 \% \mathrm{CL}\end{array}$ & $\mathrm{n}$ and $\gamma$ \\
\hline
\end{tabular}

From the above tables some considerations can be done:

- Respect to the measurement of the session 1 and 2 the gamma identification results were reported. In these reports the user can double check the confirmation of the Plutonium presence:

$\circ \quad$ the one without the * is obtained through the $\mathrm{Pu}$ emission lines identification in the mid-high resolution scintillator spectrum. The result is here accompanied with the Confidence Level value expressed in \%

$0 \quad$ the one with the $*$ comes from the neutron identification algorithm (like in measurement of section 1 and 2) and the Confidence Level definition is currently under development. 


\section{CONCLUSIONS}

The new patented algorithm applied to the neutron/gamma liquid scintillator spectrum allows to identify the neutron emitting sources such as $\mathrm{Cf}-252, \mathrm{Am} / \mathrm{Be}, \mathrm{U}$ and $\mathrm{Pu}$ mixtures in different measurement conditions. This paper shows this capability extensively. Moreover, the measurements were performed by following the homeland security ANSI and IEC standard constraints. The results reported in the tables from 2 to 7 clearly show that this new device exceeds the standard requirements. Most of the tests were focused on the patented neutron identification algorithm. It is worth noting that there is not any standard with requirements on neutron source identification because there is not any product on the market with this capability. CAEN staff keep the one-minute identification condition required for gamma sources identification also for the neutron sources identification. Neutron sources were placed with the same geometry and emission condition used to test the neutron alarm trigger. The standard performances were exceeded and the best performances are here resumed for convenience:

- Capability to trigger neutron alarm and identify Cf-252 source at a distance 4.5 times greater than the standard one

- Capability to trigger neutron alarm and identify $\mathrm{Am} / \mathrm{Be}$ source at a distance 2 times greater than the standard one

- Capability to trigger neutron alarm and identify a mixture of $\mathrm{Pu}$ isotopes source at a distance 25 times greater than the standard one

Moreover the new powerful and compact electronics allows the use of two different type of detectors simultaneously while keeping a small form factor. This characteristic enables a new technology with higher performance for portable radioactive isotope identifier devices which can include more detectors and perform data fusion analysis. The double detector capability improves the identification performance of the gamma emitters. A high-resolution inorganic scintillator, such as $\mathrm{LaBr}_{3}$ or $\mathrm{CeBr}_{3}$, has been easily integrated into the system to perform an enhanced gamma radioisotope identification by characteristic gamma lines recognition. This solution allows for a simultaneous identification of multiple radionuclides, exceeding therefore the limits of gamma identification performed with organic liquid scintillator and Compton spectra libraries only. The added benefit of this solution is the possibility to detect a masked neutron source through the PSD algorithm performed by the liquid scintillator detector while the inorganic scintillator identifies the masking gamma emitters. The inorganic scintillator also enhances the neutron source identification as shown in Table 8 where a double confirmation of the $\mathrm{Pu}$ presence is provided to the end-user. This feature fully satisfies the requirement exposed in the introduction of the abstract "[...] illicit trafficking of Material Out of Regulatory Control (MORC) and its possible use in criminal acts has raised the necessity of new detection solutions with higher efficiency and resolution to provide a high level of accuracy in the report to the authorities". The tests presented in this paper allowed to study and develop some upgrades that are currently under implementation and will be the object of the next publication. One is the definition of a confidence level for the neutron identification algorithm, as described at the end of the previous session. The confidence level for the identification is required by the standard and the algorithm definition to evaluate the confidence level is currently under implementation in the software. In the end a confidence level expressed in percentage will be shown next to each isotope identified through the neutron algorithm. The SNM identification algorithm differs from the standard identification method of gamma lines performed through peak-search. Moreover, further analysis from the results of the neutron source identification (see Figure 1) is currently under investigation. The R\&D group identified the possibility to distinguish the measurement condition (e.g. masked sources, shielded sources, etc.) for the neutron source and want to add this type of information in the identification report.

\section{REFERENCES}

[1] Morichi, M., Fanchini, E., Mangiagalli, G. (2020). A novel portable device for gamma and neutron spectroscopy with special nuclear material identification. EPJ Web Conf., 225. https://doi.org/10.1051/epjconf/202022507006

[2] Dahl, F. (2013). Missing nuclear material may pose attack threat: IAEA. https://www.reuters.com/article/usnuclear-security-iaea/missing-nuclear-materialmaypose-attack-threat-iaea-idUSBRE95R0BV20130628.

[3] Dahl, F. (2014). Missing radioactive material may pose 'dirty bomb' threat: IAEA. https://www.reuters.com/article/us-nuclear-securityiaea/missingradioactive-material-may-pose-dirty-bombthreat-iaea-idUSBREA2K10W20140321.

[4] INTERPOL conference targets global nuclear trafficking. Jan. 2016. https://www.interpol.int/en/News-andvents/News/2016/INTERPOL-conference-targetsglobalnuclear-trafficking.

[5] World Customs Organization. WCO urges Customs administrations to actively secure borders from nuclear threats. Mar. 2012. http://www.wcoomd.org/en/media/newsroom/2012 march / wco - urges - customs - administrations - to actively -secure-borders-from-nuclear-threats.aspx.

[6] Nuclear Security Systems and Measures for Major Public Events. Implementing Guides 18. Vienna: INTERNATIONAL ATOMIC ENERGY AGENCY, 2012. ISBN: 978-92-0-127010-8. https://www.iaea.org/publications/8858/nuclearsecurity-systems-and-measures-formajor-public-events.

[7] International Atomic Energy Agency. Nuclear Security Plan. https:/www.iaea.org/ topics/security-of-nuclearand-other-radioactive-Material/nuclearsecurity-plan.

[8] Incident and Trafficking Database (ITDB). Incidents of nuclear and other radioactive material out of regulatory control.

https://www.iaea.org/sites/default/files/19/04/itdbfactsheet-2019.pdf.

[9] Charles D. Ferguson and William C. Potter. The Four Faces of Nuclear Terrorism. New York: Routledge, 2005. https://doi.org/10.4324/9780203956922

[10] Bunn, M.G., Maslin, E.P. (2011). All stocks of weaponsusable nuclear materials worldwide must be protected against global terrorist threats. Journal of Nuclear Materials Management, 39(2): 21-27. http://nrs.harvard.edu/urn-3:HUL.InstRepos:30209097.

[11] National Research Council. (2002). Making the nation safer: The role of science and technology in countering terrorism. National Academies Press. https://www.nap.edu/catalog/10415/making-thenationsafer-the-role-of-science-and-technology. 
[12] Downes, R., Hobbs, C., Salisbury, D. (2019). Combating nuclear smuggling? Exploring drivers and challenges to detecting nuclear and radiological materials at maritime facilities. The Nonproliferation Review, 26(1-2): 83-104. https://doi.org/10.1080/10736700.2019.1610256

[13] Beaumont, J.S., Lee, T.H., Mayorov, M., Tintori, C.,
Rogo, F., Angelucci, B., Corbo, M. (2017). A fastneutron coincidence collar using liquid scintillators for fresh fuel verification. Journal of Radioanalytical and Nuclear Chemistry, 314(2): 803-812. https://doi.org/10.1007/s10967-017-5412-x 